\title{
Applications of low-cost 3D imaging techniques for the documentation of heritage objects
}

\section{Aplicaciones de técnicas de imágenes 3D de bajo costo para documentación de bienes culturales}

\author{
M. Morita1, G. Bilmes ${ }^{1,2, *}$ \\ 1. Laboratorio de Ablación, Limpieza y Restauración con Láser, Centro de Investigaciones Ópticas (CONICET- \\ UNLP-CIC). Camino Centenario and 508, Gonnet, La Plata, Argentina, Casilla de Correo 3, (1897). \\ 2. Facultad de Ingeniería, Universidad Nacional de La Plata. Calle 1 y 47, La Plata, Buenos Aires, Argentina, \\ (B1900TAG) \\ ${ }^{(*)}$ E-mail: gabrielb@ciop.unlp.edu.ar
}

\author{
Received: 19/02/2018 Accepted: 18/06/2018 \\ DOI: $10.7149 /$ OPA.51.2.50026
}

\begin{abstract}
:
3D image recording has reached an increasing impact on the field of cultural heritage. Applications include documentation of the state of conservation and dimensions of an object, the archaeological survey of artefacts, the dissemination of museum collections and sites, and packaging designing, among others. The 3D image acquisition techniques most commonly used are laser or structured light scanning and, increasingly, close range digital photogrammetry. In this work a 3D digitization casestudy is presented in order to explore the advantages and possibilities of close range digital photogrammetry respect to scanning techniques in documentation of heritage objects. Free and lowcost software used by these techniques were tested and the quality of the results obtained in each case is analyzed. The potentiality of close range digital photogrammetry to enhance the resolution of the $3 \mathrm{D}$ recording is also discussed.
\end{abstract}

Key words: close range digital photogrammetry; structure from motion; laser scanning; structured light scanning; 3D imaging; cultural heritage; documentation.

\section{RESUMEN:}

El registro de imágenes 3D ha tenido un impacto creciente en el campo de los bienes culturales. Las aplicaciones incluyen la documentación del estado de conservación y de las dimensiones de un objeto, el estudio arqueológico de artefactos, la difusión de las colecciones de museos y sitios y el diseño de embalaje, entre otros. Las técnicas de adquisición de imágenes 3D comúnmente más usadas son el escaneo con láser y con luz estructurada y, cada vez más, la fotogrametría digital de objeto cercano. En este trabajo, se presenta un estudio de caso de digitalización 3D para explorar las ventajas y posibilidades de la fotogrametría digital de objeto cercano respecto a las técnicas de escaneo en documentación de bienes culturales. Se probaron software gratuitos y de bajo costo y se analizó la calidad de los resultados obtenidos en cada caso. También se discute la potencialidad de la fotogrametría digital de objeto cercano para optimizar la resolución.

Palabras clave: fotogrametría digital de objeto cercano; structure from motion, escaneo láser; escaneo de luz estructurada; imágenes 3D; bienes culturales, documentación.

\section{REFERENCES AND LINKS / REFERENCIAS Y ENLACES}

[1] M. Levoy, K. Pulli, B. Curless, S. Rusinkiewicz, D. Koller, L. Pereira, M. Ginzton, "The Digital Michelangelo Project: 3D Scanning of Large Statues", Proc. Conf. Computer Graphics and Interactive Techniques (SIGGRAPH) 131-144 (2000). 
[2] R. Fontana, Ma. Greco, M. Materazzi, E. Pampaloni, L. Pezzati, C. Rocchini, R. Scopigno. "ThreeDimensional Modelling of Statues: the Minerva of Arezzo", J Cult Herit. 3(IV), 325-331 (2002).

[3] G. Guidi, J.A. Beraldin, C. Atzeni, "High Accuracy 3D Modeling of Cultural Heritage: The Digitizing of Donatello's Maddalena”, IEEE Transactions on Image Processing, 13, 370-380 (2004).

[4] G. Sansoni, F. Docchio. "3-D Optical Measurements in the Field of Cultural Heritage: The Case of the Vittoria Alata of Brescia”, IEEE Trans. Instr. Meas, 54, 359-368 (2005)

[5] F. Blais, J. Taylor, L. Cournoyer, M. Picard, L. Borgeat, L.G. Dicaire, M. Rioux, J.A. Beraldin, "Ultra-HighResolution Imaging at 50 $\mu \mathrm{m}$ using a Portable XYZRGB Color Laser Scanner", Int. Workshop on Recording, Modeling and Visualization of Cultural Heritage, Ascona, Switzerland (2005)

[6] B. Ducke, D. Score, J. Reeves, "Multiview 3D Reconstruction of the Archaeological Site at Weymouth from Image Series", Comput Graph, 35(II), 375-382 (2011).

[7] G. Verhoeven, D. Taelman, F. Vermeulen, “Computer Vision-based Orthophoto Mapping of Complex Archaeological Sites: The Ancient Quarry of Pitaranha (Portugal-Spain)”, Archaeometry, 54: 11141129 (2012).

[8] L. Forest Collado, "New Methods for Triangulation-based Shape Acquisition using Laser Scanners" Ph.D. thesis, Universitat de Girona, p. 150 (2004).

[9] J.C. Torres, P. Cano, J. Melero, M. España, J. Moreno, “Aplicaciones de la digitalización 3D del patrimonio," Virtual Archaeol. Rev., 1, 51-54 (2010)

[10] M. Schaich, "Combined 3D Scanning and Photogrammetry Surveys with 3D Database Support for Archaeology \& Cultural Heritage". A practice report on ArcTron's Information System aSPECT3d, 233246 (2013).

[11] W. Wei, A. de Tagle, I. Hummelen, Three-Dimensional Documentation of Two-Dimensional Works of Art, In: Salimbeni, Renzo; Pezzati, Luca (Eds). Optical Methods for Arts and Archaeology, Proceedings of the SPIE, No 5857, 52-61 (2005).

[12] F. Lamolda Álvarez, P. Cano Olivares, "Registro mediante la utilización de scanner láser 3D del estado previo a la intervención de la Fuente de los Leones”, In: Taller CICOP FINAL V3. Universitat Politécnica de Valencia 1(II) (2010).

[13] M. Callieri, M. Dellepiane, R. Scopigno, Modelli digitali 3D per il supporto al restauro: riassemblaggio digitale e ricostruzione virtuale, In: Arbace and Sonnino (Eds.) La madonna di Pietranico: Storia, restauro e ricostruzione di un'opera in terracotta. Pescara: Edizioni ZIP. 74-82 (2011),

[14] K. Lambers, H. Eisenbeiss, M. Sauerbier, D. Kupferschmidt, T. Gaisecker, S. Sotoodeh, T. Hanusch, "Combining Photogrammetry and Laser Scanning for the Recording and Modeling of the Late Intermediate Period site of Pinchango Alto, Palpa, Peru” Journal Archaeol. Sci., 34, 1702-1712 (2007).

[15] T. Van Damme, "Computer Vision Photogrammetry for Underwater Archaeological Site Recording", University of Southern Denmarck (2015)

[16] E. Alby, E. Smigiel, P.Assali,P.Grussenmeyer, I.Kauffmann-Smigiel, “Low cost Solutions for Dense Point Clouds of Small Objects: Photomodeler Scanner vs. David Laserscanner”, 22nd CIPA Symposium, Kyoto (October 11-15, 2009).

[17] M. Samaan, R. Héno, M. Pierrot-Deseilligny. "Close-Range Photogrammetric Tools for Small 3D Archeological Objects” Int. Arch. Photogramm. Remote Sens. Spat. Inf. Sci. 40, no. September, 2-6 (2013).

[18] L.M. Galantucci, M. Pesce, F. Lavecchia, "A Powerful Scanning Methodology for 3D Measurements of Small Parts with Complex Surfaces and Sub Millimetre-sized Features, based on Close Range Photogrammetry", Precision Engineering, 43, 211-219 (2016).

[19] R. Marroquim, A. Sá, K. Rodrigues, V. Balbio, R. Zamorano, "Digitising Ivory Artefacts at the National History Museum in Brazil”, Eurographics Workshop on Graphics and Cultural Heritage (2017).

[20] O.C. Wei, C.S. Chin, Z. Majid, H. Setan, "3D Documentation and Preservation of Historical Monument Using Terrestrial Laser", Geoinformation Science Journal 10(I), 73-90 (2010).

[21] S. Zheng, Y. Zhou, R. Huang, L. Zhou, X. Xu, C. Wang, "A method of 3D measurement and reconstruction for cultural relics in museums”, XXII ISPRS Congress, 25 August - 01 September 2012, Melbourne, Australia, International Archives of the Photogrammetry, Remote Sensing and Spatial Information Sciences, vol. XXXIX-B5, 145-149 (2012). 
[22] S.M. Seitz, B. Curless, J. Diebel, D. Scharstein, R. Szeliski, “A Comparison and Evaluation of Multi-View Stereo Reconstruction Algorithms", Proceedings of the IEEE Computer Society Conference on Computer Vision and Pattern Recognition, 1(I), 519-526 (2006).

[23] H.M. Yilmaz, "Importance of Digital Close-Range Photogrammetry in Documentation of Cultural Heritage”, J Cult Herit. 8(IV), 428-433 (2007).

[24] R. Opitz, K. Simon, A. Barnes, K. Fisher, "Close-Range Photogrammetry vs. 3D Scanning: Comparing Data Capture, Processing and Model Generation in the Field and the Lab", Proceedings of the computer applications and quantitative methods in archaeology (CAA), Avenue Campus, University of Southhampton, England, March 26-29 (2012)

[25] A. Koutsoudis, V. Vidmar, F. Arnaoutoglou, "Performance Evaluation of a Multi-Image 3D Reconstruction Software on a Low-Feature Artefact”, Journal of Archaeological Science, 40(XII), 44504456 (2013).

[26] L. McCarthy, "Multi-Image Photogrammetry as a Practical Tool for Cultural Heritage Survey and Community Engagement" J. Archaeol. Sci., 43, 175-185 (2014).

[27] T.C. Dumitriu, "Towards digital preservation of Repedea's big quarry outcrop using "StructurefromMotion" photogrammetry tools", Analele Științifice ale Universității "Al. I. Cuza" din Iași. Seria Geologie. Tome. 59 (2), 19-40 (2013).

[28] A. Mathys, J. Brecko, P. Semal, “Comparing 3d digitizing technologies: what are the differences?” Proc. of Digital Heritage International Congress, Oct. 28-Nov. 1, 2013, Marseille, Vol. 1, 201-204 (2013).

[29] E. Georgiou, E. Karachaliou, E. Stylianidis, "3D Representation of the 19th century balkan architecture using scaled museum-maquette and photogrammetry methods", The International Archives of the Photogrammetry, Remote Sensing and Spatial Information Sciences, Volume XLII-2/W5, (2017) 26th International CIPA Symposium 2017, 28 August-01 September 2017, Ottawa, Canada.

[30] F. Remondino, M.G. Spera, E. Nocerino, F. Menna, F. Nex, "State of the Art in High Density Image Matching". The Photogrammetric Record, 29(146), 144-166 (2014).

[31] S. Winkelbach, S. Molkenstruck, F.M. Wahl, "Low-Cost Laser Range Scanner and Fast Surface Registration Approach” 28th DAGM Symp. Proc., No.1, 718-728 (2006).

[32] R.Y. Tsai, “An Efficient and Accurate Camera Calibration Technique for 3-D Machine Vision”. IEEE Int. Conference on Computer Vision and Pattern Recognition, Miami, USA, 364- 374 (1986).

[33] B. Triggs, P.F. McLauchlan, R.I. Hartley, A.W. Fitzgibbon, Bundle Adjustment - A Modern Synthesis, In: B. Triggs, A. Zisserman \& R. Szeliski, (eds). ICCV '99 Proceedings of the International Workshop on Vision Algorithms: Theory and Practice. London: Springer-Verlag, 298-372 (2000).

[34] N. Snavely, S.M. Seitz, R. Szeliski, "Modeling the World from Internet Photo Collections" In: Int. J. Comput. Vision, 80(II), 189-210 (2008).

[35] M.J. Westoby, J. Brasington, N.F. Glasser, M.J. Hambrey, J.M. Reynolds, "Structure-from-Motion photogrammetry: A Low-Cost, Effective Tool for Geoscience Applications", Geomorphology, 179, 300314 (2012).

[36] R. Szeliski, "Computer Vision: Algorithms and Applications”, Texts in Computer Science, SpringerVerlag London Limited, London (2011)

[37] J.C. Torres, G. Arroyo, C. Romo, J. De Haro, “3D Digitization using Structure from Motion”, CEIG - Spanish Comput. Graph. Conf., 1-10 (2012).

[38] M. Corsini, M. Dellepiane, F. Ganovelli, F. Gherardi, A. Fusiello, R. Scopigno, "Fully Automatic Registration of Image Sets on Approximate Geometry" Int J Comput Vis, 102(1-3), 91-111 (2013).

[39] D. Tingdahl, L. Van Gool, "A Public System for Image Based 3D Model Generation" Comput. Vision/Computer Graph. Collab. Tech. 5th Int. Conf. MIRAGE (2011).

[40] Y. Furukawa, J. Ponce, "Accurate, Dense, and Robust Multi-View Stereopsis". Proceedings, IEEE Conference on Computer Vision and Pattern Recognition (CVPR), 17-22 June, Minneapolis, USA , 1-8 (2007).

[41] C. Wu, "VisualSFM: A Visual Structure from Motion System" http://homes. cs. washington. edu/ ccwu/vsfm. (2011)

[42] Y. Furukawa, B. Curless, S.M. Seitz, R. Szeliski, "Towards Internet-Scale Multi-View Stereo" Proceedings of the IEEE Computer Society Conference on Computer Vision and Pattern Recognition, CVPR 2010 San Francisco, CA, United States, 1434-1441 (2010). 
[43] M. Jancosek, T. Pajdla, "Multi-View Reconstruction Preserving Weakly-Supported Surfaces" IEEE Conference on Computer Vision and Pattern Recognition. (Version 0.6.0) [software] (2012).

[44] P. Cignoni, M. Callieri, M. Corsini, M. Dellepiane, F. Ganovelli, G. Ranzuglia, "MeshLab: an Open-Source Mesh Processing Tool” Eurographics Italian Chapter Conference, Salerno (2008).

[45] M. Kazhdan, M. Bolitho, H. Hoppe, "Poisson Surface Reconstruction and its applications" Proceedings of the 2008 ACM Symposium on Solid and Physical Modeling, Stony Brook, New York (2008).

[46] M. Kazhdan, "Estimating the Laplace-Beltrami Operator by Restricting 3D Functions" (version 1) [software] http://www.cs.jhu.edu/ misha/Code/TextureStitcher/ . (2009).

[47] M. Chuang, L. Luo, B.J. Brown, S. Rusinkiewicz, M. Kazhdan, "Estimating the Laplace-Beltrami Operator by Restricting 3D functions" Proceedings of the Symposium on Geometry Processing. Eurographics Association, 1475-1484 (2009).

[48] M. Levoy, S. Rusinkiewicz, "Efficient Variants of the ICP Algorithm" In Third int. Conf. On 3D digital imaging and modeling (3dim 2001), IEEE comp. Soc., 145-152 (2001).

[49] P. Tiano, D. Tapete, M. Matteini, F. Ceccaroni, "The Micro-Photogrammetry: a New Diagnostic Tool for Onsite Monitoring of Monumental Surfaces" Proceedings of the International workshop SMW08 In situ monitoring of monumental surfaces $(2008 / 10 / 27)$

[50] H. Yanagi, H. Chikatsu, "3D Modeling of Small Objects Using Macro Lens in Digital Very Close-Range Photogrammetry" ISPRS Arch, 38, 617-622 (2010).

[51] G. Ioannakis, A. Koutsoudis, B. Vidmar, F. Arnaoutoglou, C. Chamzas, "Enhancing Multi- Image Photogrammetric 3d Reconstruction Performance on Low Feature Surfaces" Conference: CAA 2015, Sienna (2015).

\section{Introduction}

In conservation of cultural heritage 3D image acquisition is useful for recording and documentation of objects, artworks and sites [1-7]. 3D models can offer information of an artefact, namely its dimensions, the state of conservation and the characteristics of the surface. They also allow archaeological surveys, the dissemination of museum collections and archaeological sites, and packaging designing, among others.

3D models can be acquired by several techniques. The most used in cultural heritage are scanning techniques such as laser (LS) and structured light scanning (SLS), and close range digital photogrammetry (CRDP) [8-10]. Scanning techniques are more commonly used for documentation of paintings and pieces where high resolution is needed for the analysis of the conservation state or for planning restoration projects [11-13]. On the other hand, digital photogrammetry has been widely applied on documentation and virtualization of big scale scenes such as archaeological sites $(14,15)$.

Generally, conservators and archaeologists often rely more on laser and structured light scanning techniques for the detailed record of small objects in the millimetre and sub-millimetre scale, even though for these purposes the use of close range digital photogrammetry has been reported in the literature [1619]. Usually, LS and SLS are considered quite similar in terms of resolution, cost and complexity, leaving aside digital photogrammetry [20]. Nevertheless, the recent development of advanced image processing techniques opens new possibilities for CRDP for recording objects in a simpler way, with the quality and resolution of scanning techniques. While there are previous works that recognize the possibilities of CRDP for certain applications [21], there has been little systematic study comparing its advantages over other 3D techniques, mainly in terms of the most appropriate software, requirements, quality, cost and resolution [22-29]. As it was previously recognized, to adopt these techniques for accurate measurement purposes, clear accuracy statements, benchmarking and evaluations must be carried out [30].

In this work a 3D digitization case-study is presented in order to explore the advantages and possibilities of CRDP with respect to scanning techniques, in documentation of heritage objects. Different free and lowcost software used by these techniques were tested, and the quality of the results obtained in each case is analysed. The potentiality of CRDP to enhance the resolution of the 3D recording is also discussed.

\section{Materials and methods}

The 3D recording was performed on a small Pre-Inca Peruvian terracotta sculpture, which is a small fragment of a handmade ceramic vessel (Fig. 1). The size is $5.2 \mathrm{~cm} \mathrm{x} 4.6 \mathrm{~cm} \times 4.2 \mathrm{~cm}$. 


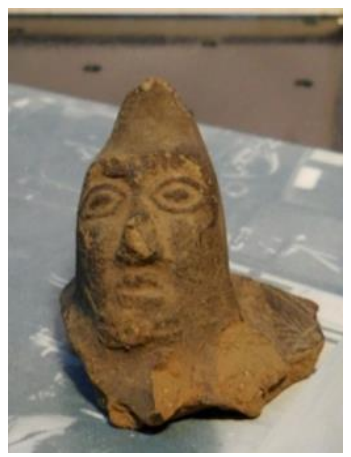

Fig. 1. Photograph of small Pre-Inca Peruvian terracotta sculpture used for 3D recording.

LS, SLS and CRDP were used for the 3D recording. LS was performed with a red laser module $(5 \mathrm{~mW}, 650$ $\mathrm{nm}$ ) which impinges on a cylindrical lens to generate a laser plane that intercepts the object. DavidLaserscanner software [v.3.10.4] was used. This software has the advantage of a real time self-calibration that allows handheld movement of the laser plane [31]. A Thorlabs $1645 \mathrm{c}$ camera with a resolution of $1280 \times 1024$ px was used for recording the images. Two calibration panels made of paperboard with the reference pattern [32] from David-Laserscanner were arranged at $90^{\circ}$. The object was positioned in the center of the corner, and the laser was placed at $25 \mathrm{~cm}$ distance. The thickness of the laser line projected on the object was $<1 \mathrm{~mm}$ and well defined. The intersection angle between the laser beam and the camera axis was $30^{\circ}$. The laser line was perpendicular to the eyes axis of the sculpture and the sweep was made in the horizontal direction by using a stepper motor of a resolution of $2,5 \mu \mathrm{m}$. Images were captured at $10 \mathrm{fps}$. The object had to be rotated $15^{\circ}$ for each new scan. 25 scans were acquired ( 5 minutes per scan). The different scans were aligned and fused also using David-Laserscanner.

SLS was performed with the same system used for LS, but replacing the laser by an Epson PowerLite 52c projector of $1200 \mathrm{~lm}$, positioned to the right of the camera, at $25^{\circ}$. Fifty-eight patterns were projected on the object, using the phase shifting method in David-Laserscanner, in both vertical and horizontal directions, and the time between each projection was $1 \mathrm{~s}$. A total of 27 scans were acquired. The different scans also were aligned and fused using David-Laserscanner.

CDRP with Structure from Motion (SFM) was applied [33-36]. The camera used was a Nikon Coolpix L22 with a NIKKOR lens 3.6x, f3.1-6.7, 37-134 mm. 80 ISO, f/3.1, 1/160 s, and a fixed focal length were the setup conditions. Natural diffuse and uniform lighting was used; images were obtained outdoors, on a cloudy day. They were taken in RAW and then converted to JPEG format 4000x3000 px size, and a resolution of $300 \mathrm{ppi}$. The images were used as input in each SFM software system.

As SFM needs each feature of the object to be present in many photographs -when only two images are available, algorithms may have errors that make impossible the 3D reconstruction [37,38]-, the camera was moved around the object, in a wide range of orientations and positions. To optimize the resolution of the 3D model, we use as a first criterion the condition that the whole object completely fills the camera frame. A second criterion was used to determine the optimal number of photos. The best number is related to the overlap of the images needed to record all the prominences of the object. Considering that, independently of the size of the object, a minimum of $70 \%$ of overlap between adjacent images is necessary for CRDP, the minimum number of photos that the user needs to keep this overlap is 8 (for a simple shape object such as a cube or a cylinder, for example). This would be the number of images taken in a single path (for recording one plane of the geometry of the object). To complete the whole 3D geometry, it would be necessary to change the angle of the camera, and add two new paths, in order to record the top and the low part of the object. Then, the minimum number of images to cover a very simple object is 24 . After several tests with the SFM software systems, we found that in our case 35-45 was the number of images required, in order to achieve a complete mesh of the whole object without deformations. Thus, we used 40 photos.

Different software systems based on SFM were used and compared. The criterion used for selecting the software systems was that they were widely used, free and/or open source. One of them is Arc3D [39], developed by the VISICS research group of the KU Leuven in Belgium, which works online uploading the photographs with the creation of a user account. Also, we used Autodesk (C) 2015 [software] 123D Catch, an online software application as Arc3D. In the latter case images were uploaded to a server for processing, 
involving PMVS (Patch-based Multi-View Stereo) [40]. We then tested Microsoft Corporation. Photosynth 2015 [software], a user-friendly free software application from Microsoft Live Labs and the University of Washington. In this case images were uploaded to a web service and the generated sparse point cloud could be transformed to a denser one using the Photosynth Toolkit, containing PMVS and CMVS (Clustering Views for Multi-view Stereo) tools. Finally, VisualSFM [41], an open source software system from Washington University, Seattle, was combined with CMVS [42]. The SFM output of VisualSFM was also input in CMPMVS, a software package used to generate textured meshes [43].

The hardware used for processing Structure from Motion and performing image processing was a 64-bit system with Intel@ Core $^{\mathrm{TM}}$ i7-4770 CPU @ $3.40 \mathrm{GHz}$ processor, equipped with NVIDIA GeForce GTX 760 with 2GB GDDR5 CUDA support and 8GB of RAM. On the other hand, the hardware used for laser and structured light scanning was a 32-bit system, Intel Core $^{\mathrm{TM}} 2$ Duo CPU T5870 @ 2.00GHz and 2 GB of RAM. MeshLab [44], an open image processing software system from the Istituto di Scienza e Tecnologie dell'Informazione "A. Faedo", Pisa, was used to generate and align textured meshes from dense point clouds. Poisson filter [45] and VCG Reconstruction filter, a reconstruction algorithm provided by MeshLab, were used for surface reconstruction. MeshLab was also used for scaling, taking measures virtually and editing the 3D models.

For calculating the deformation in the 3D models, CloudCompare [v. 2.7.0 StereoGPL software] (CC), a free software for processing 3D point clouds, was used.

Texture Stitcher [v.1, software] was used for performing texture-stitching on meshes [46,47]. It was applied on the resulted mesh after aligning different textured meshes.

In all cases the resolution of the 3D model was determined by comparing the distance between two points of the 3D model and a measurement in the real object, performed with a calliper of $0.02 \mathrm{~mm}$ resolution. A WILD M5A stereomicroscope 20X was also used for micro-photogrammetry.

\section{Results}

\section{3.a. 3D model obtained by Close Range Digital Photogrammetry}

The 3D model obtained with Arc3D was very simple to be processed. This is an advantage of this application respect to most of 3D reconstruction software systems, whose installation and operation are not trivial. In this sense Arc3D generated a textured mesh automatically, without needing special hardware. However, in our case, results show meshes with background noise attached to the main mesh, and a mismatched texture. After cleaning the background with MeshLab, we obtained an incomplete mesh with a resolution no better than $2 \mathrm{~mm}$ (Fig. 2a). Another problem of using this application is that because the user cannot participate in the reconstruction process, the feature matching and the point cloud generation cannot be controlled.

When using Autodesk 123D Catch, we obtained a mesh with an uniform smooth texture and a resolution no better than $1.5 \mathrm{~mm}$ (Fig. 2b). The required time for online processing was 15 minutes. In 123D Catch the user cannot take part in the reconstruction process, except for improving the matching between images that were not aligned in the previous steps. In our case, it was not necessary to improve the result.

Photosynth and VisualSFM + CMVS give point clouds instead of meshes. The point cloud obtained with Photosynth had a lower resolution (6.815 points after cleaning) than the one obtained with VisualSFM + CMVS (307.600 points after cleaning). These point clouds were turned into meshes by applying a Poisson filter in MeshLab. The parameters were: Octree Depth 11 and Solver Divide 11. The mesh obtained by Photosynth had a low resolution $(\sim 1 \mathrm{~cm})$ without any details (Fig. 2c). On the other hand, the mesh obtained by VisualSFM + CMVS was of a higher resolution $(\sim 1 \mathrm{~mm})$ but with a slight grainy surface (Fig. 2d). Finally, the mesh obtained by VisualSFM + CMP-MVS has the highest quality without grainy surface (Fig. 2e). Also with this software, the obtained mesh has colored texture and vertices which improve visual comprehension (Fig. 2f). The CMP-MVS process for the 40 images took half an hour, using the hardware mentioned in section 2. The point cloud obtained by CMP-MVS consists of 2.045 .825 points after cleaning. This mesh was selected to be compared with the other $3 \mathrm{D}$ acquisition techniques. The resolution of the obtained 3D model was between 200-400 $\mu$ m depending on the region of the object (see Fig. 3a). 

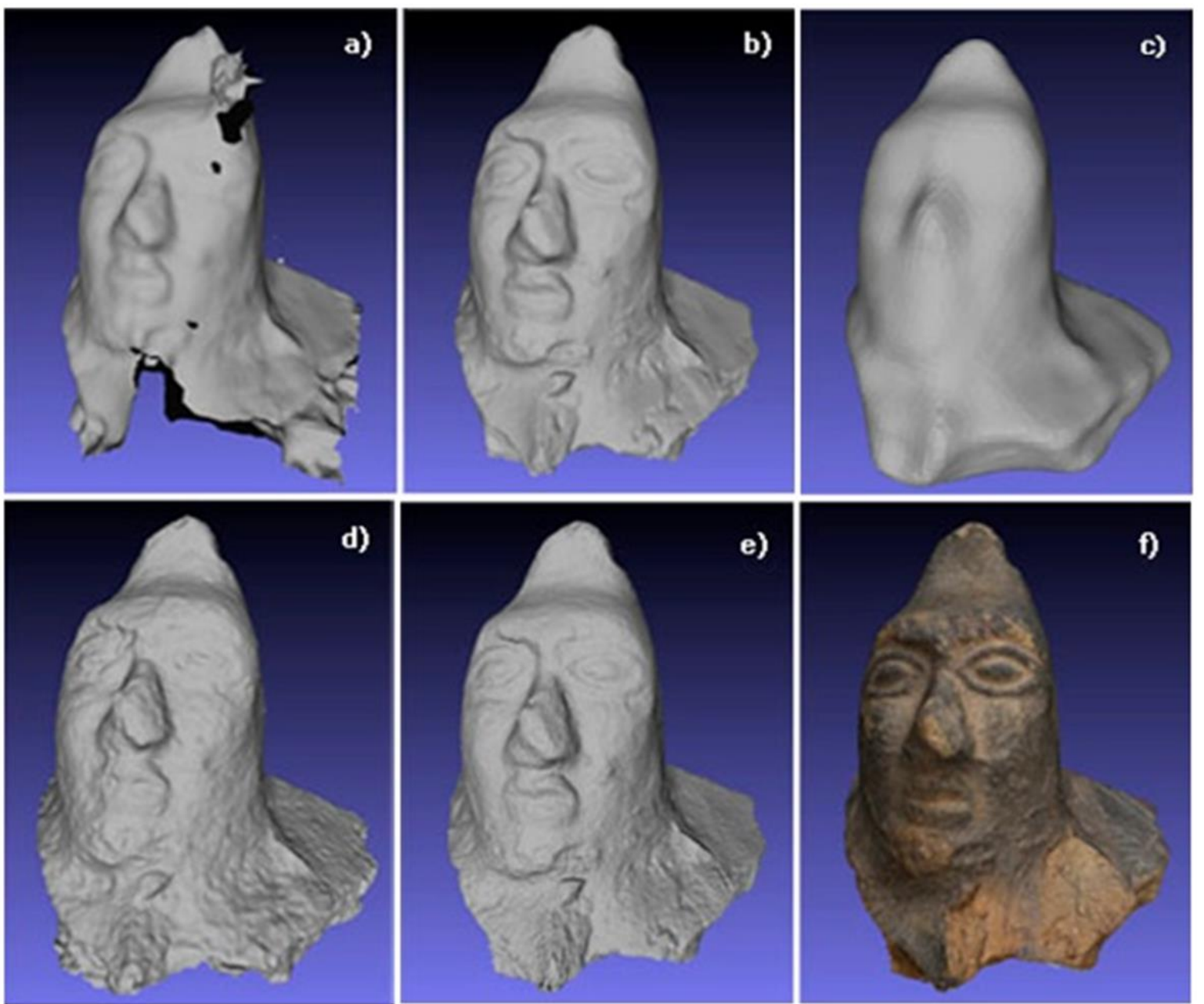

Fig. 2. Comparison of meshes obtained by different software systems. a) Arc3D. b) Autodesk 123D Catch. c) Photosynth. d) VisualSFM + CMVS. e) VisualSFM + CMP-MVS. f) Textured mesh obtained by Visual + CMP-MVS.

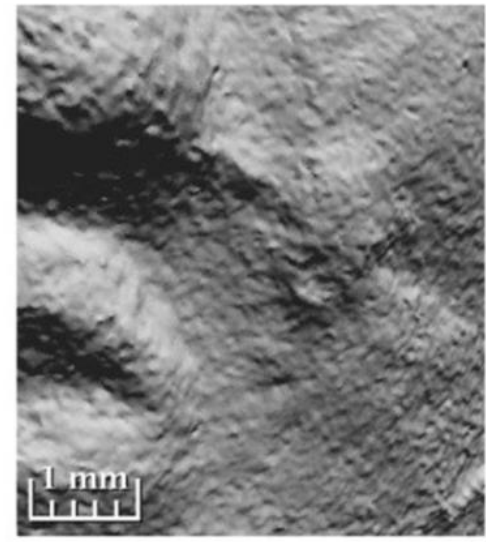

(a)

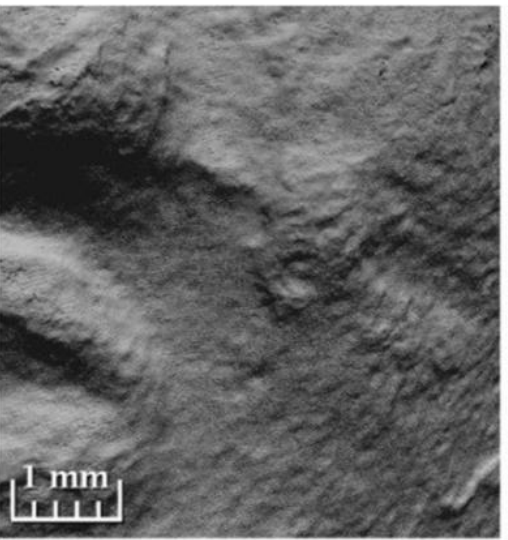

(b)

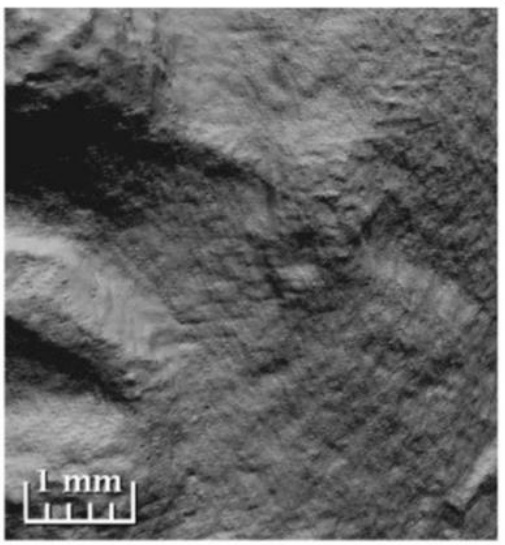

(c)

Fig. 3. Detail of the 3D model obtained by (a) VisualSFM + CMP-MVS, (b) Structured light scanning and (c) Laser scanning.

It is worth mentioning that VisualSFM can process a larger number of images compared to the other software systems. Another advantage of this program is that the user can take part in the feature matching, 
using its own sequence pairs, or using its own codes of feature detectors. The user can also adjust the parameters for speed.

\section{3.b. 3D models obtained with Structured Light Scanning and Laser Scanning}

The 3D model obtained with SLS also has a resolution between 200-400 $\mu \mathrm{m}$ that represents a resolution of the order of $0.06 \%$ of the maximum dimension of the object (Fig.3b).

Handheld Laser scanning gave good quality 3D images, but with thin vertical lines related to the "sweep" of the laser. This can happen when the frequency of image acquisition is less than the speed of the sweep. This effect was removed when using the stepper motor. The resolution achieved by laser scanning was also in the same order of SLS and CRDP (Fig. 3a and Fig. 3c)

The time needed to clean, align and fuse all the scans in each scanning method was about an hour, using David-Laserscanner and MeshLab.

\section{3.c. Summary table}

Table 1 summarizes a comparison of the three most used low-cost 3D techniques, in terms of software used, requirements, cost, quality and resolution.

TABLE 1. Comparison of results obtained with CRDP, SL and SLS and its performance when using different software systems.

\begin{tabular}{|c|c|c|c|c|c|c|c|}
\hline Technique & Software & Output & $\begin{array}{c}\text { Additional } \\
\text { requirements }\end{array}$ & Cost & $\begin{array}{c}\text { Quality of the } \\
\text { results }\end{array}$ & \multicolumn{2}{|c|}{$\begin{array}{l}\text { Resolution of the final point } \\
\text { cloud / mesh }\end{array}$} \\
\hline \multirow{5}{*}{ CRDP } & Arc3D & textured mesh & no & no & $\begin{array}{c}\text { Poor. } \\
\text { Incomplete } \\
\text { mesh, } \\
\text { mismatched } \\
\text { texture. }\end{array}$ & \multicolumn{2}{|c|}{$2 \mathrm{~mm}$} \\
\hline & $\begin{array}{c}\text { Autodesk } \\
\text { 123D Catch }\end{array}$ & textured mesh & no & no & $\begin{array}{l}\text { Good. Complete } \\
\text { mesh with } \\
\text { regular texture. }\end{array}$ & \multicolumn{2}{|c|}{$1.5 \mathrm{~mm}$} \\
\hline & Photosynth & point cloud & $\begin{array}{l}\text { 3D model needs } \\
\text { surface } \\
\text { reconstruction. }\end{array}$ & no & $\begin{array}{l}\text { Very poor. No } \\
\text { details at all. }\end{array}$ & $\begin{array}{l}6.815 \text { points } \\
\text { after cleaning }\end{array}$ & $\begin{array}{c}1 \mathrm{~cm} \\
\text { (after Poisson } \\
\text { reconstruction) }\end{array}$ \\
\hline & $\begin{array}{c}\text { VisualSFM + } \\
\text { CMVS }\end{array}$ & point cloud & $\begin{array}{c}\text { Hardware } \\
\text { requirements } \\
\text { for image } \\
\text { processing. 3D } \\
\text { model needs } \\
\text { surface } \\
\text { reconstruction. }\end{array}$ & no & $\begin{array}{l}\text { Good, but with } \\
\text { grainy surface. }\end{array}$ & $\begin{array}{c}307.600 \text { points } \\
\text { after cleaning }\end{array}$ & $\begin{array}{l}\text { (after Poisson } \\
\text { reconstruction) }\end{array}$ \\
\hline & $\begin{array}{c}\text { VisualSFM + } \\
\text { CMP-MVS }\end{array}$ & $\begin{array}{l}\text { both textured } \\
\text { and vertex } \\
\text { color mesh }\end{array}$ & $\begin{array}{l}\text { Hardware } \\
\text { requirements } \\
\text { for image } \\
\text { processing. }\end{array}$ & no & Very good. & $\begin{array}{c}2.045 .825 \\
\text { points after } \\
\text { cleaning }\end{array}$ & $200-400 \mu \mathrm{m}$ \\
\hline LS & $\begin{array}{c}\text { David- } \\
\text { Laserscanner }\end{array}$ & $\begin{array}{l}\text { mesh (also } \\
\text { possibility for } \\
\text { texturing) }\end{array}$ & $\begin{array}{c}\text { A setup for } \\
\text { scanning. Mesh } \\
\text { alignment. }\end{array}$ & low & $\begin{array}{l}\text { Good, but thin } \\
\text { vertical lines } \\
\text { related to the } \\
\text { "sweep" of the } \\
\text { laser can appear } \\
\text { in the 3D } \\
\text { model. }\end{array}$ & $200-4$ & $0 \mu \mathrm{m}$ \\
\hline SLS & $\begin{array}{c}\text { David- } \\
\text { Laserscanner }\end{array}$ & $\begin{array}{c}\text { mesh (also } \\
\text { possibility for } \\
\text { texturing) }\end{array}$ & $\begin{array}{c}\text { A setup for } \\
\text { scanning. Mesh } \\
\text { alignment. }\end{array}$ & low & Very good. & $200-4$ & $0 \mu \mathrm{m}$ \\
\hline
\end{tabular}

\section{3.d. Analysis of the deformation of the 3D models}

In order to estimate the possible deformation of the 3D models we performed two types of analysis. On one hand, we compared the distance between two points in the model with respect to the one obtained in the real object. We performed this procedure with pairs of points in different directions. The comparison was 
made in the same region of a single scan obtained by LS and SLS, and the same region of the model obtained by CRDP. Results show accuracy for CRDP and SLS of 99.7\% in any direction. For LS, we obtain an accuracy of $96.2 \%$ in the horizontal direction (eyes axis) and $99.2 \%$ in the vertical one (perpendicular to the direction of the laser sweep).

Taking into account this result we made a second type of analysis by using CC software. A region of $2 \mathrm{~cm} \mathrm{x}$ $1 \mathrm{~cm}$ corresponding to part of the left eye and cheek was selected to observe possible deformations in the models. Also, this region was part of a single scan. First, the meshes were aligned by using the ICP based range map registration tool of MeshLab [48]. The aligned meshes were converted into dense point clouds with CC. After that, a new alignment was made in CC. Once the point clouds were well superimposed, the next step was computing the distances between two point clouds. A local modelling was performed in CC, in order to get a better estimation of the distance. In this case, the Quadric (formerly called 'Height function') local model was chosen. In figure 4 the resulting scalar field's color scale for the three pair point clouds comparison is shown.
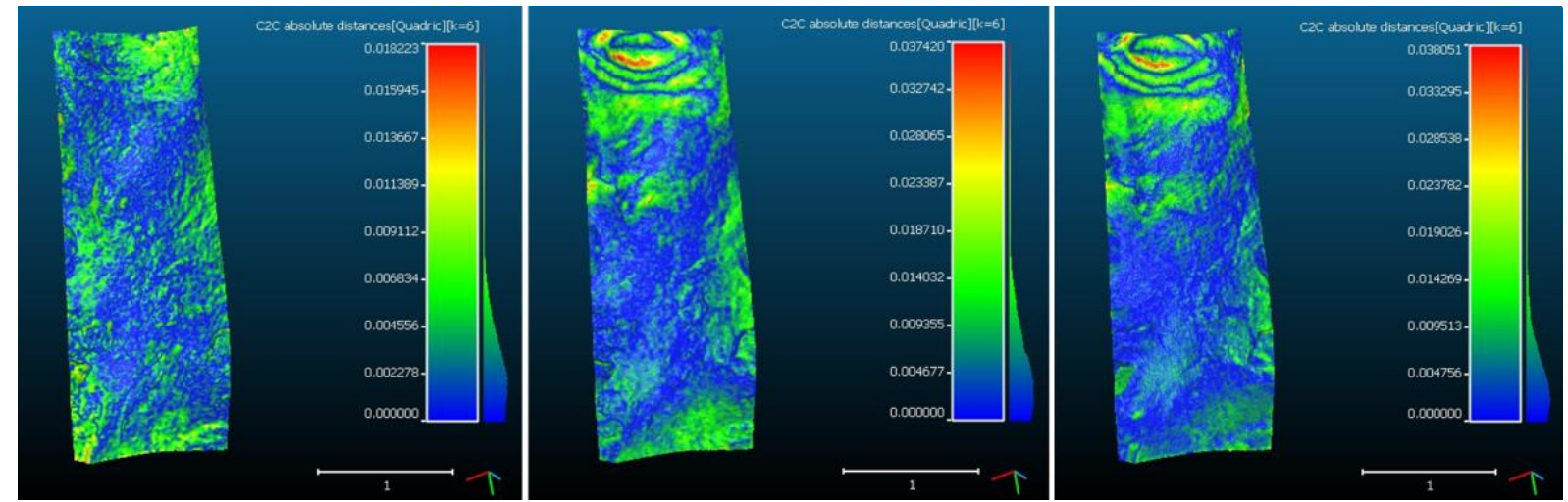

Fig. 4. Scalar field's color scale for distance comparison of three pairs of point clouds. From left to right: selected area of the point cloud obtained by CRDP, compared to the corresponding area in the point cloud obtained by SLS; the same area of the 3D model obtained by CRDP, compared to the corresponding area in the point cloud obtained by Laser; the same area in the point cloud obtained by Laser, compared to the corresponding area in the point cloud obtained by SLS. Red indicates that there is greater difference in the pair of point clouds; blue indicates a smaller difference.

As it can be seen comparing the models from SLS and CRDP almost no difference was observed. On the contrary comparing models from LS with respect to SLS and CRDP important differences are observed that can affect distance measurements. These results are consistent with the measurements discussed in the first part of this section.

\section{3.e. Optimization of the resolution of the CRDP 3D model}

The resolution of the 3D model obtained with CRDP can be improved taking into account that it depends on several parameters. For a given camera and object, it depends mainly on the number of images, determining the overlap level of the 3D recording. To optimize the resolution as a function of the number of photos we tried different sets of images in VisualSFM + CMVS. The aim was to achieve the densest point cloud. 37, 32, 27,19 , and 7 were the number of images in each set, decreasing the overlap. As it is shown in figure 5 , at least 27 images were the minimum required to obtain a dense point cloud.

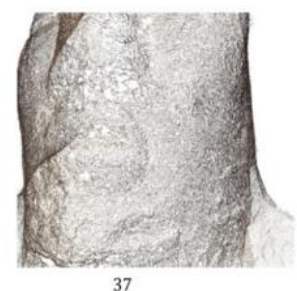

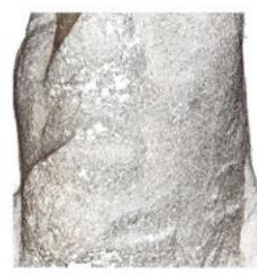

32

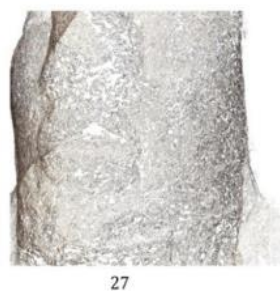

27

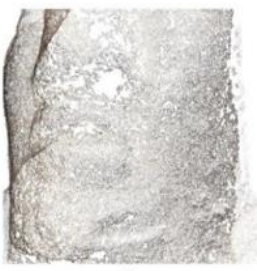

19

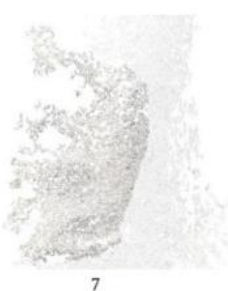

Fig. 5. Point clouds generated by VisualSFM + CMVS with different sets of images in order to determine the required overlap to achieve a denser point cloud. 37, 32, 27, 19 and 7 were the number of images in each set, decreasing the overlap. 
One advantage of CRDP with respect to SLS and LS is that it is very easy to improve the resolution of the 3D models by using magnified images obtained by a camera with a macro lens or a microscope $[49,50]$. With the aim of recording a deterioration of the sculpture consisting of a hole of $700 \mu \mathrm{m}$ diameter, a new set of images was recorded by using a microscope 20X. Fifteen images were taken with an overlap of more than $80 \%$. The retrieved 3D image is shown in figures $6 \mathrm{a}$ and $6 \mathrm{~b}$. Figure $6 \mathrm{c}$ also shows the same features, but in this case, the input data were recorded without optical magnification.

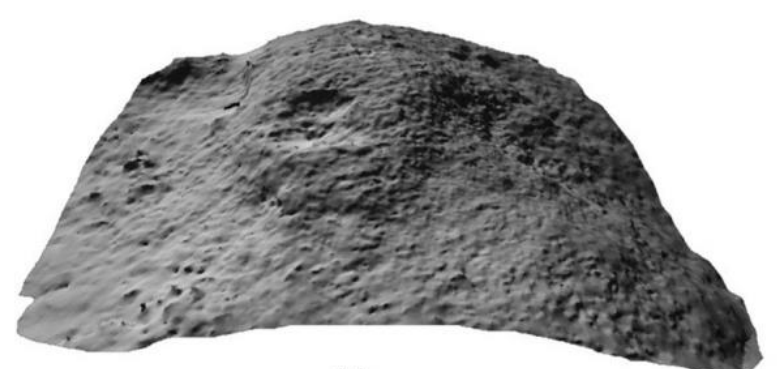

(a)

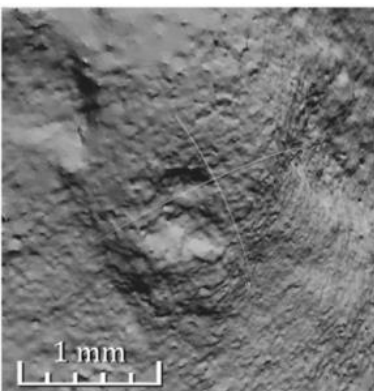

(b)

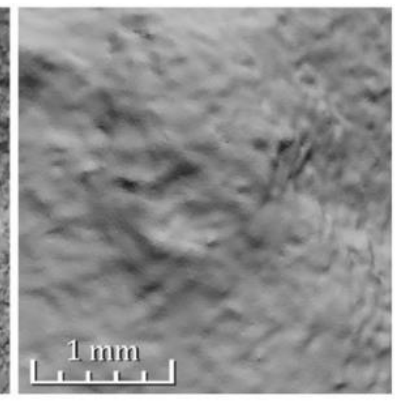

(c)

Fig. 6. a) and b) 3D model of a deterioration of the sculpture, obtained by taking the photos with a microscope 20X. c) The same detail when it was registered without optical magnification.

\section{3.f. Post-processing}

In order to build the whole sculpture (also with the base), three different colored meshes were produced with VisualSFM + CMP-MVS, and different sets of photos. The MeshLab's alignment tool was used for aligning the meshes and the VCG Filter was applied in order to merge them in a single mesh. One problem found in the final 3D image is the uniformity of the texture. Due to lighting variation in the color across the different meshes, combining them in a single one produces a discontinuity of the color at meshes transitions (see Fig. 7a). Thus, the three original meshes and a new mesh obtained with the Poisson filter was processed with the Texture Stitcher software system. As it is explained by the author of this software system, a color gradient field is defined over the base mesh. While its divergence is computed, the best fitted color field to the gradients is returned by a Poisson system. The result was an improved textured mesh, with a soft color transition (Fig. 7b).

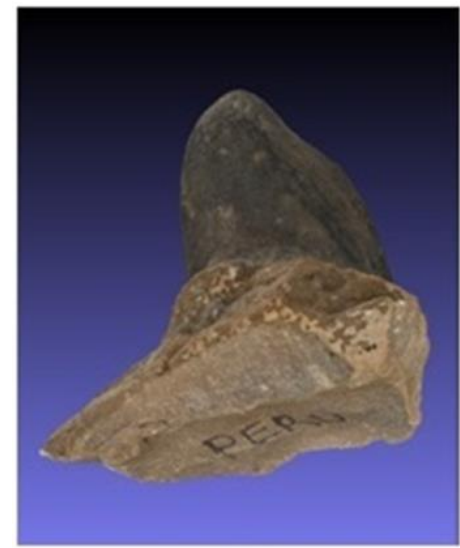

(a)

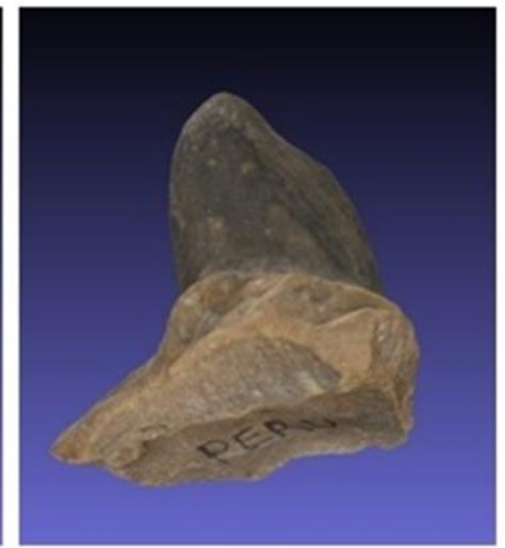

(b)

Fig. 7. a) Back of the 3D model of the sculpture showing the discontinuity of the texture. b). The same 3D model improved after applying Texture Stitcher.

\section{Conclusions}

3D models of a small Pre-Inca Peruvian terracotta sculpture were performed by using Structured Light Scanning, Laser Scanning and Close Range Digital Photogrammetry. Free, open-source software systems were used for processing. With the three techniques, a resolution between 200 and $400 \mu \mathrm{m}$, depending on 
the region of the object, was achieved. These values represent a resolution of the order of $0.06 \%$ of the maximum dimension of the object.

The combination of VisualSFM and CMP-MVS resulted to be the software that better generated a complete textured mesh with a suitable resolution, in comparison to Arc3D, Photosynth and 123D Catch.

It is known that the main limitations of commercial scanners are mainly their cost and complexity. However, as it was shown in this paper, low cost software such as David-Laserscanner, and free 3D image processing software such as MeshLab, offer practical solutions when scanning simple small objects. In spite of that, CRDP with VisualSFM + CMP-MVS has important advantages over LS and SLS techniques. It is cheaper and easier to use and, in this particular case, the whole process to achieve a textured 3D mesh can be made in a shorter time. Required instruments are only a camera and a computer, devices that are available in all museums. As well as for the scanning techniques, if the 3D images obtained are not good enough, image processing may be applied for improving the texture, cleaning or aligning the meshes. For implementing the stereo matching in objects without textures we observed that CRDP has limitations over LS and SLS, because it needs corresponding features between images. However, it is possible to avoid this problem by projecting noise function-based patterns (51].

The quality of the surface of the 3D model was different in each technique. In the case of laser scanning it depended on the quality of the line and sweep speed. The alignment and fusion were important too, which was also relevant in structured light scanning. On the other hand, CRDP with Structure from Motion using this approach reached the same order of resolution as SLS and LS, as long as the overlap of the images is sufficient to achieve denser point clouds.

In the case of SLS and CRDP almost no deformation was observed comparing the 3D models. On the contrary, LS produces a deformation of the mesh compared to SLS and CRDP that affects distance measurements.

Micro-photogrammetry is another advantage of CRDP, which allows recording small details of objects. Although it is known that laser and structured light scanning can be combined with microscopy, the setup used for performing this task is very complex and difficult to handle with.

We conclude that close range digital photogrammetry with VisualSFM and CMP-MVS is the cheapest, practical and suitable technique for the 3D digitization and documentation of submetre-size heritage objects.

\section{Acknowledgements}

We thank Dr. Gustavo Torchia from CIOP and Dr. Andrés Bilmes from IPGP - CENPAT for their very fruitful comments.

\section{Funding Body}

This work was partially supported by by Project 11/I199, Facultad de Ingeniería, Universidad Nacional de La Plata and by the European Commission Seventh Framework Programme under grant agreement FP7INFRASTRUCTURES-2012-1-313193 (ARIADNE). María M. Morita is postdoctoral fellow at Consejo Nacional de Investigaciones Científicas y Técnicas (CONICET). Gabriel M. Bilmes is member of the Comisión de Investigaciones Científicas de la Provincia de Buenos Aires (CIC-BA) and Facultad de Ingeniería of the Universidad Nacional de La Plata (FI-UNLP). 